\title{
One Teen's Journey from Local Math Club to Professional Publication
}

\section{Scott Hershberger}

On a long flight from Boston to Atlanta, eighth grader Milena Harned was pondering a geometry problem involving perimeter bisectors and angle bisectors of quadrilaterals. As she looked at some examples, she noticed an intriguing pattern. By the time the plane landed, Harned had made a breakthrough that would lead not to an " $\mathrm{A}$ " on a homework assignment, but to her first publication in a professional, peer-reviewed mathematics journal.

"Perimeter bisectors, cusps, and kites" 1 appeared in the October 2021 issue of the International Journal of Geometry, when Harned was just 16. Publishing a new result at such a young age sets Harned apart from other teens with a knack for mathematics. Yet her achievement is a natural next step in her education-she has long explored open-ended mathematics problems outside of school.

In fifth grade, Harned joined Girls' Angle, ${ }^{2}$ a Cambridge, Massachusetts-based club where girls learn math through investigation and discovery. The students follow their curiosity and creativity, guided by mentors who have proven original mathematical theorems.

"It was one of the most invaluable experiences I've had," Harned says. "It definitely got me to pursue some [less common] topics in math, especially at a younger age than I would have ever considered to do them."

Girls' Angle gave Harned the opportunity not just to hone her problem-solving skills, but also to practice

Scott Hershberger is the communications and outreach content specialist at the AMS. His email address is s1h@ams.org.

1 https://ijgeometry.com/product/milena-harned-perimeter -bisectors-cusps-and-kites/

${ }^{2}$ http: //www.girlsangle.org/

For permission to reprint this article, please contact: reprint-permission @ams.org.

DOI: https://dx.doi.org/10.1090/noti2446

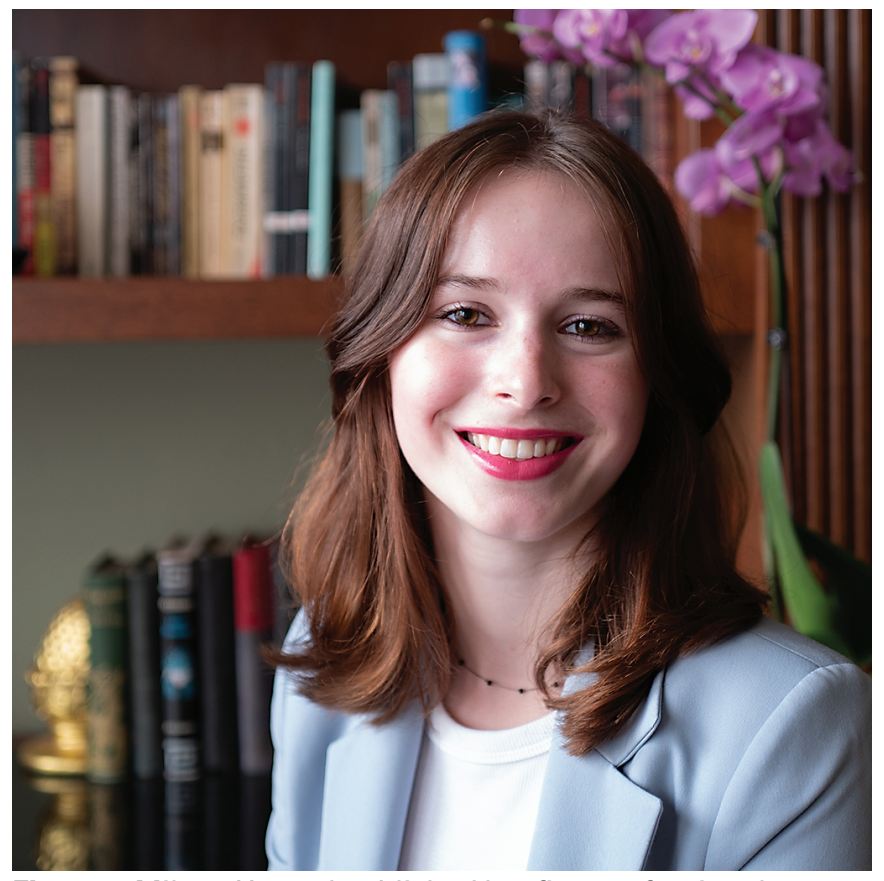

Figure 1. Milena Harned published her first professional, peerreviewed mathematics paper at the age of 16.

explaining her work through writing. In the span of two and a half years, she authored or co-authored 10 articles in the Girls' Angle Bulletin, the organization's bimonthly magazine. It bridges high school and professional mathematics, providing a venue for students who go above and beyond to share their work. For a decade, the AMS has published the magazine at a subsidized cost through its print shop in Pawtucket, Rhode Island, as a service to the community.

As her mathematical skills grew, Harned also received private lessons from Girls' Angle founder and president Ken Fan, who describes her as a "fountainhead" of new ideas. 
"She's actually the only student I've ever had who I did not have to set an agenda for at all," he says. "She's really quite phenomenal."

\section{Proving a New Theorem}

Harned's first article in the Bulletin, which she wrote in sixth grade, discussed the volume of a regular $n$-simplex (the generalization of a tetrahedron). Her subsequent articles about a Fibonacci-like sequence and counting all possible ways to play a game of Nim garnered her two entries ${ }^{3}$ in The On-Line Encyclopedia of Integer Sequences.

Fan saw a clear progression in the sophistication of Harned's ideas and the clarity of her exposition as the middle schooler continued writing up her work. Harned agrees that publishing in the Bulletin played a key role in helping her reach the professional level.

"It helped me realize that [...] in order to write something up, I need to know everything about it. [...] That was a really difficult process at first," she says. "Learning how to convey my thoughts really helped me get a more wellrounded understanding of math."

In seventh grade, Harned began the work that culminated in her first professional publication. Out of curiosity, she looked at lines that divide the perimeter of a polygon in half. The set of these perimeter bisectors defines a curve called an envelope-but depending on the polygon, the envelope might or might not be continuous. After analyzing some examples, Harned was able to prove that the only triangles with continuous envelopes are equilateral ones. So she moved on to convex quadrilaterals.

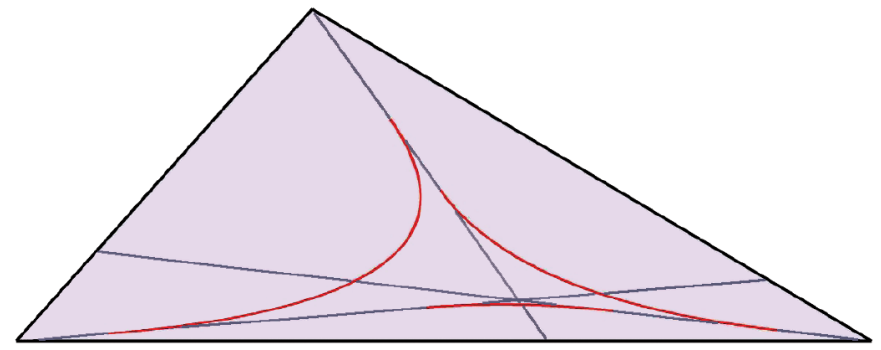

Figure 2. The envelope (in red) of a scalene triangle is not continuous.

The four-sided case turned out to be more complicated. Harned knew that the envelope would be continuous if all the angle bisectors were also perimeter bisectors. But classifying all possible quadrilaterals with this property eluded her until that flight to Georgia, nearly a year after she began working on the problem.

Her key realization was that any continuous envelope must have an odd number of sharp cusps, which corresponded to the perimeter bisectors that pass through vertices. In the case of quadrilaterals, that meant that one

${ }^{3}$ A286983 and A289329 perimeter bisector must pass through two vertices. A few technical details remained before the proof would be complete, but "in the moment it just felt correct," she says.

Later that summer, she filled in the final missing piece, arriving at her new theorem: In a given convex quadrilateral, every angle bisector also bisects the perimeter if and only if the quadrilateral is either a kite with three congruent acute angles or a rhombus.

\section{An International Journey}

Before formally writing up her results, Harned had to shift her attention to a more pressing challenge: starting her first year of high school. Not until the COVID-19 lockdown did she have the chance to return to her research.
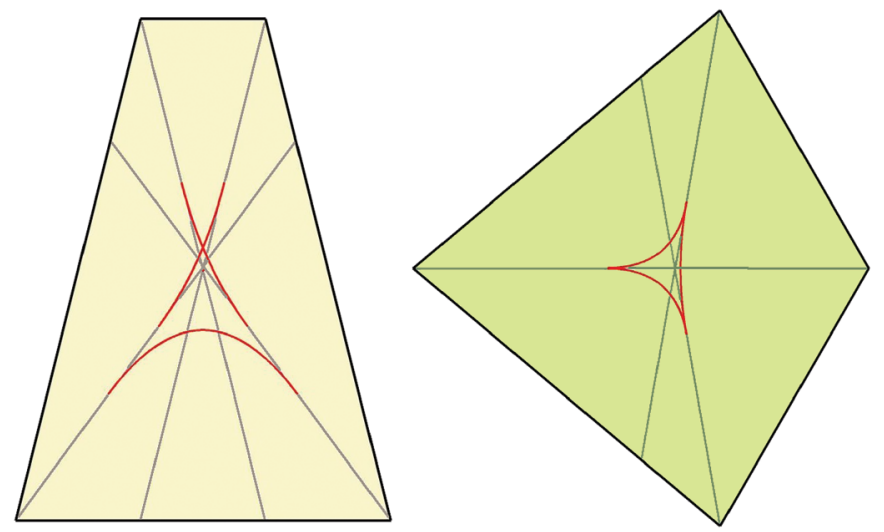

Figure 3. A trapezoid (left) and a kite (right) with their envelopes (red) and perimeter bisectors (grey). The kite has a continuous envelope with three cusps, and one perimeter bisector passes through a pair of vertices.

Although writing articles in the Girls' Angle Bulletin had prepared Harned for this larger project, it was easy to lose sight of her passion for mathematics in the midst of the day-to-day work.

"There was a period of time when writing it up that I was like, 'Okay, I just want this done. I want to get this over with,'" she says. "But it was really important for me to ground myself and think, 'You know, I really love this stuff. I need to remember that."

By July 2020, her paper was complete, so she sent it to the International Journal of Geometry for review. Throughout the writing process, she had benefited from feedback from Fan. Now, mathematicians she had never met would judge whether her work was worthy of publication.

"For the first month or so I would check my email almost every day, thinking, 'Is [the decision] here yet?'" Harned says. "Then I sort of just put it out of my mind, let myself not worry about it."

Soon afterward, she moved to Switzerland to enroll in an International Baccalaureate program, skipping 10th grade entirely. In February of 2021, she learned that her paper had been accepted pending minor revisions. 


\section{AMS COMMUNICATION}

Harned was overjoyed, as was her mentor. "For me, it's thrilling-it feels better than the feeling I have when I publish one of my own papers," Fan says. "I'm excited for her that she's starting to get professional recognition."

\section{A Bright Future}

During the pandemic, Girls' Angle meetings have shifted to an online format, but the time difference between Massachusetts and Switzerland has prevented Harned from participating for now. She hopes to serve as a club mentor once she returns to the US for college. She plans to major in mathematics and then pursue a PhD in the field.

"If there's some sort of lab where I can apply the math I know to help some people create something new [...] I think that would be something I'd look to do," she says. "Math is my passion, but I also want to use it in a way that will help the world."

Harned's paper is the first peer-reviewed publication by a Girls' Angle member, but Fan is confident it will not be the last. Harned is now collaborating with another member on a paper about intersections of lines in the plane. Fan attributes these results, as well as novel findings published by Harned and others in the Girls' Angle Bulletin, in large part to the club's emphasis on open-ended exploration rather than math competitions.

According to Fan, the traditional metrics of math competitions, which reward fast, accurate thinking, would likely not recognize Harned's talent. "She actually thinks so fast that she often stumbles on herself," says Fan. "Her mode of operation is to plow ahead and just worry about [errors] as they come. [...] She doesn't seem to mind seeing a lot of wrong things." Yet this approach is perfectly suited to the creative problem-solving needed to prove new theorems, he says.

Harned's trajectory is a testament to the importance of mentorship in cultivating the next generation of mathematicians.

"I don't think I would have ever considered math as something more than a school subject that I got good grades in had I not gone [to Girls' Angle]," Harned says. "I got to better understand how I think, and that's really helped me in my schoolwork and in the math I do as I've gotten older-just to understand my own mind."

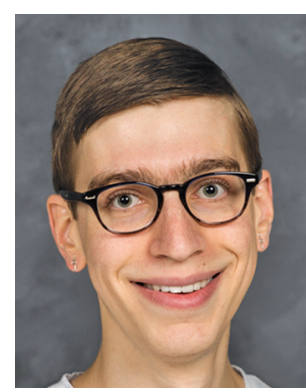

Scott Hershberger

\section{Credits}

Figure 1 is courtesy of Tony Capozzi.

Figures 2 and 3 are courtesy of Milena Harned. Author photo is courtesy of Jiyoon Kang.
Please make sure that Notices and Bulletin find their new home.

Update your address at www.ams.org/member-directory.

You can also send address changes to amsmem@ams.org or:

Sales and Member Services American Mathematical Society 201 Charles Street

Providence, RI 02904-2213 USA

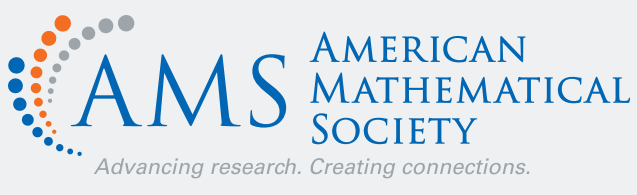

